\title{
Study of the structure of metal materials using microanalysis
}

\author{
Marina N. Bulaeva ${ }^{1}$, Olga I. Vaganova ${ }^{2}$, Zhanna V. Smirnova ${ }^{3}$,Lyubov Yu. Shobonova ${ }^{4}$, \\ Elena A. Chelnokova ${ }^{5}$ \\ ${ }^{1}$ Minin Nizhny Novgorod State Pedagogical University, Nizhny Novgorod, Russia, bulaevamarina @ mail.ru \\ ${ }^{2}$ Minin Nizhny Novgorod State Pedagogical University, Nizhny Novgorod, Russia, vaganova_o@ rambler.ru \\ ${ }^{3}$ Minin Nizhny Novgorod State Pedagogical University, Nizhny Novgorod, Russia, z.v.smirnova@ mininuniver.ru \\ ${ }^{4}$ Minin Nizhny Novgorod State Pedagogical University, Nizhny Novgorod, Russia, 1.love80@mail.ru \\ ${ }^{5}$ Minin Nizhny Novgorod State Pedagogical University, Nizhny Novgorod, Russia, chelnelena@ gmail.com
}

\begin{abstract}
Microanalysis provides the ability to determine the structure of metals with the naked eye and using a microscope. Microanalysis allows you to determine the types of shapes and sizes of grains, inclusions of foreign phases, the presence of micro-voids and their location. Before conducting the study, the sample slots made from the part are prepared. The quality of the manufactured strip affects the accuracy of determining the structural structure. Their surface is polished to a mirror Shine and etched with special reagents.
\end{abstract}

Key words: Microanalysis, metal, alloys, grinding, polishing.

\section{INTRODUCTION}

Various properties of structural materials depend on the chemical composition, structure and structure. There is a need to study them in order to get an idea of specific materials. The metal microstructure is a structure «that can be detected using an optical microscope that allows you to distinguish the dimensions of at least $0.2 \mathrm{~mm}$ » [1]. «The microscope allows you to magnify the image 2000 times. The process of studying the microstructure is called microanalysis» [1].

In the microanalysis of thin sections are used. The slot is made to study one of the planes of the material sample.

A clamp was used for the study (the figure is presented by O.Yu. Vaulina) [2].

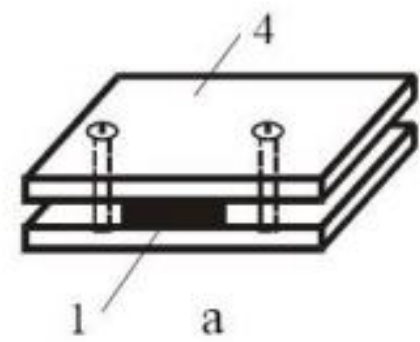

Figure 1: Slot clamped in the clamp

After grinding, polishing was performed. GOI paste was used for polishing.

The study allowed us to study the structure of metal materials.

\section{THEORETICAL FRAMEWORK}

Microanalysis is the process of studying the structure of metals and alloys using a metallographic microscope that magnifies 50-2000 times. In the process of microanalysis, microslips are produced and examined using a metallographic microscope. Microslips are a sample of a metal or alloy that is used for microanalysis. In the process of grinding the sample surface, you cannot go immediately from the skin with a large grain to the skin with a small grain and press the sample hard to complete the task faster. As a rule, this causes a strong heating of the sample and the introduction of abrasive grains into the metal, which reduces the probability of obtaining a good quality strip.

In the process of studying the structure of metal materials, grinding and polishing is carried out.

Polishing is a process aimed at obtaining a mirror surface of the slot without drawing.

Can be applied:

- mechanical;

- chemical-mechanical;

- electro-mechanical polishing methods.

When polishing, the following rules are used:

- the slot is located on the polishing wheel further from the center;

- the contact of the surface of the slot with the soft cloth of the polishing wheel should be without distortions and too strong pressure;

- the polishing wheel is constantly wetted.

Polishing is considered complete when the surface of the slot acquires a noticeable mirror Shine without special equipment [2].

After finishing polishing, the strip is washed with water, alcohol and dried. The surface should be mirror-like, without visible scratches. To identify the structure of the plume is placed in a reagent or applied locally with cotton wool and kept for a certain time until signs of etching appear. Then it is washed again in water and dried [2].

To identify the structure of the alloy, etching is used. Etching is the effect of acids, alkalis and salts on the surface of the test sample [3]. The essence of the process of detecting the structure of metal and alloy using etching is the different degree of dissolution and staining of individual structural components:

- grains [4]; 
- solid solution;

- chemical compounds [5].

A sign of etching - surface dimming.

For etching cast iron and steel, a four-percent solution of nitric acid in alcohol is used [6]. To perform etching of aluminum alloys, a $0.5 \%$ solution of fluoric acid in water [7].

Individual structural components are dissolved by the etcher [8]. Only in this case, some are stronger, others are weaker. Therefore, under a microscope, you can see different reflections of light from more etched particles and from less etched ones [9]. Some particles may appear light, while others may appear dark [10].

It is worth noting that the quality of the manufactured strip will «affect the accuracy of determining the structural structure [11]. Using microanalysis, it is possible to determine the smallest grains, the quality of heat treatment, and detect the smallest metal defects» [1], such as cracks [12].

MIM-7 and MIM-8 metallographic microscopes are used for the study. MIM-7 consists of:

- illuminator's;

- bodies;

-top.

Figure (according to G. V. Klevtsov) is shown in figure 2 [13].

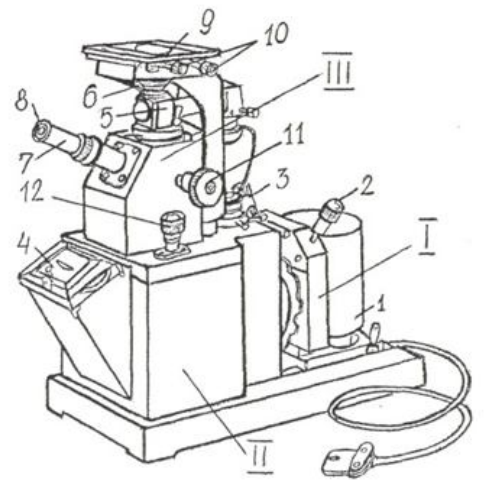

Figure 2: Metallographic microscope MIM-7

The structure of MIM-7 is represented by the following components:

- hardware diaphragm Assembly;

- lighting magnifier frame;

- system for photographing microstructure on a photographic plate;

- landing gear;

- porthole tube;

- lens;

- visual tube;

- eyepiece;

- specimen stage;

- macrometric screw;

- microscopic screw [12].

On the object table is a hole through which you can watch microsection.

The MIM-8 microscope has a similar structure except that its illumination and photography systems are located horizontally.

\section{RESULTS AND DISCUSSION}

The purpose of the study is to study the microstructure of the proposed material using microanalysis.

The following materials and equipment were used for the research:

- metallographic microscope;

- diagram of the optical system of the microscope;

- steel and cast iron samples;

- emery sharpener;

- sanding skin with different grit numbers;

- GOI polishing machine and polishing paste;

- reagents for etching;

-alcohol;

- filter paper;

- cotton.

At the beginning of the study, microslips were prepared. A sample was cut out for this purpose. The most optimal samples for the study were those with a diameter and height of 10-12 millimeters (shown in figure 3 , according To G. V. Klevtsov) [13].

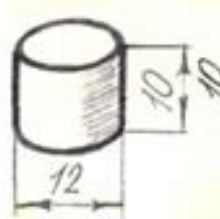

a)

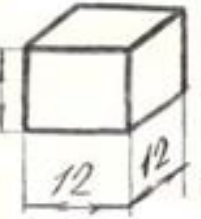

б)
Figure 3: Metallographic samples for research

Small cross-section samples (wire and sheets) were also used. They were mounted by filling in a special mandrel and fixed in clips (figure 4, according To G. V. Klevtsov) [13].
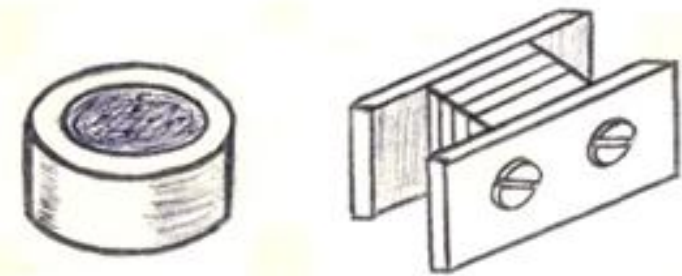

Figure 4: Metallographic samples for research

The surface of the sample was sanded and polished using an emery sharpener. Sanding was carried out both manually on thick glass, and using a sanding machine [13].

First, grinding is carried out on a skin with a large abrasive grain, then on a fine-grained skin.

With each transition to a finer skin, the surface of the sample was rubbed with cotton wool. Then the sample is rotated $90^{\circ}$ so that the risks from the previous grinding stage are located perpendicular. Sanding is carried out until the marks from the previous sanding completely disappear.

Then the sample surface was polished using the following methods:

- mechanical (chemical-mechanical);

- electrolytic. 
The purpose of polishing was to remove the marks after grinding and obtain a shiny mirror surface of the sample. Mechanical polishing was performed using a felt-covered machine.

A thin layer of GOI paste was applied to the felt. A polished surface was pressed against the rotating part of the machine. Polishing was carried out until the drawings completely disappeared.

To check the quality of the polished surface, it was viewed in a metallographic microscope at a magnification of 50 times.

After polishing, the sample was washed with water, the surface was wiped with cotton wool, previously soaked in alcohol. Then drying was performed using filter paper. Then the sample surface was etched. Since it is difficult to judge the structure of the alloy by the mirror surface of the sample, non-metallic inclusions (sulfides and oxides) are used. Therefore, to identify the microstructure, the surface is subjected to etching. Inhomogeneous sections of the studied metals and alloys become visible under the microscope. Figure 5 shows the microstructure of single-phase brass after firing and rolling (presented by L. G. Petrova and co-authors).

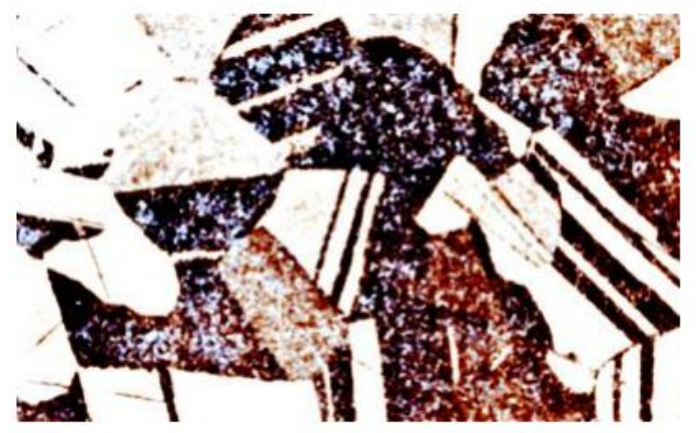

Figure 5: Microstructure of single-phase brass after rolling and firing

Figure 6 shows the microstructure of steel (presented by L. G. Petrova and co-authors) [14].
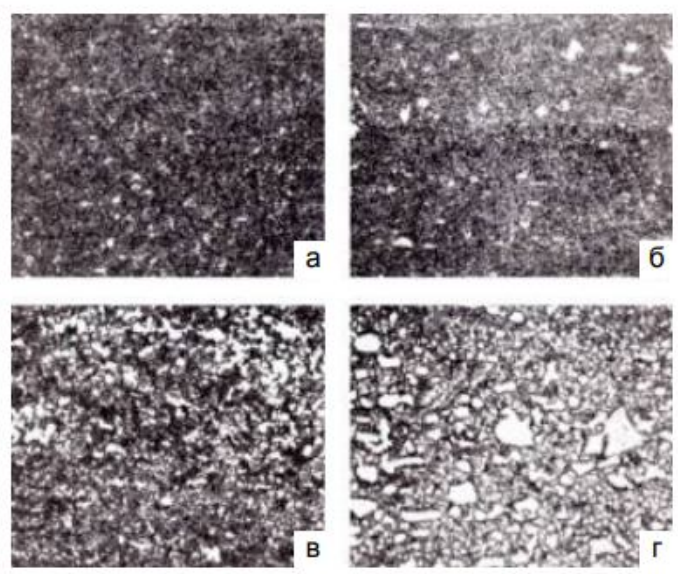

Figure 6: Microstructure of steel

Where a - slight carbide heterogeneity, b, C, d-significant carbide heterogeneity.

Microanalysis makes it possible to see the distribution of carbides. A clear idea of the nature of their distribution can be obtained by increasing by 100 times [14].
Etching of the plume was carried out by wetting it with an etcher using cotton wool and a pipette [15]. The duration of etching was several seconds [16].

At the final stage of the etching process, the microplate was washed with water and dried using filter paper [17].

The quality of etching was checked using a microscope [18]. The composition of the etcher depends on the sample material. The study analyzed carbon steels and cast iron. Table 1 shows the etchants that have been used and can be used in the etching of carbon steels and cast iron.

Table 1: Etchants used for microanalysis of cast iron and carbon steels

\begin{tabular}{|l|l|l|}
\hline $\begin{array}{l}\mathrm{P} / \mathrm{p} \\
\text { No. }\end{array}$ & Reagentcomposition & Predn Assigning \\
\hline 1 & $\begin{array}{l}\text { Ethyl alcohol (100 } \\
\text { milliliters), HMO soluti } \\
\text { on (1-5 milliliters) }\end{array}$ & $\begin{array}{l}\text { Designed to detect pearlite, } \\
\text { ferrite grain boundaries, } \\
\text { martensite and trostite } \\
\text { structures }\end{array}$ \\
\hline 2 & $\begin{array}{l}\text { Picric acid (4 } \\
\text { grams), HC 1 solution (3 } \\
\text { milliliters), water (100 } \\
\text { milliliters) }\end{array}$ & $\begin{array}{l}\text { Designed for grain } \\
\text { boundary detection in } \\
\text { hardened steel }\end{array}$ \\
\hline 3 & $\begin{array}{l}\text { Picric acid (4 grams), } \\
\text { ethyl alcohol (100 } \\
\text { milliliters) }\end{array}$ & $\begin{array}{l}\text { Designed to identify } \\
\text { nitrided and cemented } \\
\text { layers }\end{array}$ \\
\hline
\end{tabular}

Table 2 was used for visual observation of the microstructure (according To G. V. Klevtsov) [13].

Table 2 : Microscopemagnificationtable

\begin{tabular}{|c|c|c|c|c|c|}
\hline \multirow{2}{*}{\multicolumn{2}{|c|}{ Lenses }} & \multicolumn{4}{|c|}{ Eyepieces } \\
\hline & & 7 & 10 & 15 & 20 \\
\hline 8.6 & $\begin{array}{l}F=23,20, A= \\
0.17\end{array}$ & 60 & 90 & 130 & 170 \\
\hline 14.4 & $\begin{array}{l}\mathrm{F}=13,89, \mathrm{~A}= \\
0,30\end{array}$ & 100 & 140 & 200 & 300 \\
\hline 24.5 & $\begin{array}{l}\mathrm{F}=8.16, \quad \mathrm{~A}= \\
0.37\end{array}$ & 170 & 240 & 360 & 500 \\
\hline 32.5 & $\begin{array}{l}\mathrm{F}=6.16, \quad \mathrm{~A}= \\
0.65\end{array}$ & 250 & 320 & 500 & 650 \\
\hline
\end{tabular}

An eyepiece was inserted into the opening of the visual tube. Using the rotation of the micrometer screw, the object table was raised and the lens was inserted into the landing hole, which is located in the upper part of the porthole tube. The object table is lowered.

The slide table was installed so that the lens was in the center of the hole of the slide table. The dried strip is placed on the object table with the etched and polished side.

With the help of observation in the eyepiece, an accurate focus was made. The slide table is moved using screws and the structure was viewed in different places of the slot.

\section{CONCLUSION}

Microanalysis allowed us to determine the shape and size of the crystalline grains that are components of the metal; to determine the changes that occurred in the internal structure of the alloy, which occurred during chemical and heat 
treatment and after mechanical action on the alloy; to identify the resulting microcracks, shells, and non-metallic inclusions (sulfides and oxides).

\section{REFERENCES}

1. R.S. Akhmetkhanov. Application of computer technologies and the theory of fractals in the study of images of micro thin sections. Problems of machinery and automation, 3, 153-161. 2013.

2. O.Yu.Vaulina. Laboratory workshop: Methodological instructions for performing laboratory work on the course"General materials science and technology of materials" Publisher. TPU, 2012 . 10 p.

3. Z.V. Smirnova, O.I. Vaganova, O.T. Cherney, E.V. Romanovskaya, N.S. Andryashina, D.S. Toshin, The organization of emergency and dispatching servicing of an apartment house. International Journal of Innovative Technology and Exploring Engineering 8(9), 1477- 1480, 2019.

https://doi.org/10.35940/ijitee.I8194.078919

4. A.Kh. Valiullin, M.N. Serazutdinov, S.G. Sidorin, F.S. Khairullin. Laboratory work on the course of resistance of materials: Method. directions / Kazan. nat. research technol. un-t; Comp.:A.Kh. Valiullin, M.N. Serazutdinov, S.G. Sidorin, F.S. Khairullin. Kazan, 64,2011.

5. G.T. Klinkov. The specificity of manifestation of pedagogical communication as a special construct. Scientific Vector of the Balkans, 1, 51-52, 2018.

6. I.F. Filchenkova, Educational management of innovative activity of teachers as an object of pedagogical research. VestnikMininskogouniversiteta (Vestnik of Minin University), 2019.7 (4), 3. (in Russ.).2019.

7. Z.V. Smirnova, A.A. Rudenko, O.I. Vaganova, O.T. Cherney, D.S. Mokerov, E.A. Semakhin, The research of carbon construction steel at laser alloying. International Journal of Innovative Technology and Exploring Engineering. 2019

8. V.F. Terentyev. About endurance limit of metal materials.New materials and technology and machine-upgraded. No. 1 pp. 32-38, 2007.

9. Yu.P. Egorov, Yu.M. Lozinsky, E.I. Marr Laboratory practice materials science for students, students in the field of "Mechanical Engineering", 2015, pp. 34.

10. N.S. Abramova, O.I. Vaganova, L.I. Kutepova, Development of educational and methodological support in the context of the implementation of content and communication technologies.Baltiyskiygumanitarnyyzhurnal. Baltic Humanitarian Journal, 7, no. 2 (23), 181-184. 2018.

11. M.N. Bulaeva, O.I. Vaganova, M.N. Gladkova. Activity technologies in a professional educational institution.Baltiyskiygumanitarnyyzhurnal. Baltic Humanitarian Journal), 7, no. 3 (24), 167-170. 2018.

12. Zh.V Smirnova, O.T Cherney. Laser alloying technology when changing the processing speed.International Journal of Emerging Trends in Engineering Research, 8, no 4, 2020. https://doi.org/10.30534/ijeter/2020/40842020

13. G.V. Klevtsov. Fractodiagnostics of the destruction of metallic materials and structures: textbook. allowance / G.V. Klevtsov [et al.]. - M.: MI-CC, 2007, pp. 264.

14. L.G. Petrova, V.A. Alexandrov, P.E. Demin, S.I. Barabanov, A.S. Sergeeva, M.V. Morshchilov Study guide for the disciplines "Materials Science". MADI, $2018.56 \mathrm{p}$.

15. N.A. Barkhatov, S.E. Revunov, Zh.V. Smirnova, O.T. Cherney M.V Mukhina. Recovery of gaps in records of Geomagnetic observatories by Neural Network. International Journal of Emerging Trends in Engineering Research, 8, no 4, 1243-1246, 2020. https://doi.org/10.30534/ijeter/2020/48842020

16. C. Santhosh, K. Hari Kishore, G. Pavani Lakshmi, G. Kushwanth, P. Rama Krishna Dharma, Teja, R. S. Ernest Ravindran, S. V. Cheerala, M. R. Kumar. Detection of Heavy Metal Ions using Star-Shaped Microfluidic Channel. International Journal of Emerging Trends in Engineering Research, 7, No. 12. 2019. https://doi.org/10.30534/ijeter/2019/067122019

17. A. Zakaria, M. S. N. Ibrahi, Experimental Evaluation of Multiple Savonius Turbines in Oblique and Cluster Configuration, International Journal of Emerging Trends in Engineering Research, 7, No. 12. 2019. https://doi.org/10.30534/ijeter/2019/10712201

18. A.V. Kirjukhin, O. O. Milman, A. V. Ptakhin, V. D. Kuprjashov, Efficiency of Schemes of Active Broadband Damping of Vibration Forces Transmitted by Vibration Insulation to the Foundation, International Journal of Emerging Trends in Engineering Research, 7, No. 12. 2019. https://doi.org/10.30534/ijeter/2019/017122019 